This is a self-archived version of an original article. This version may differ from the original in pagination and typographic details.

Author(s): Lähdesmäki, Tuuli; Fenyvesi, Kristof

Title: Bridging Art and Mathematics : Introduction

Year: 2017

Version:

Copyright: @ Springer International Publishing AG 2017

Rights: In Copyright

Rights url: http://rightsstatements.org/page/lnC/1.0/?language=en

Please cite the original version:

Lähdesmäki, T., \& Fenyvesi, K. (2017). Bridging Art and Mathematics : Introduction. In K. Fenyvesi, \& T. Lähdesmäki (Eds.), Aesthetics of Interdisciplinarity : Art and Mathematics (pp. 125). Birkhäuser. https://doi.org/10.1007/978-3-319-57259-8_1 


\section{Bridging Art and Mathematics: Introduction}

Tuuli Lähdesmäki 1 Email: tuuli.lahdesmaki@jyu.fi

Kristóf Fenyvesi 1 Email: kristof.k.fenyvesi@jyu.fi

1 Department of Music, Art and Culture Studies, University of Jyväskylä, P.O. Box 35, 40014 Jyväskylä, Finland

There is a long history of interdisciplinary discussions on the relations between science, mathematics, geometry, art, aesthetics, and artistic praxes. These discussions remain active and pertinent today: the aforementioned relations are explored in various scientific communities, journals, and at conferences. Globally, numerous scholars and artists share a common interest in combining creative thinking, intellectual curiosity, and aesthetic sensibility in their work. Various experts working in different scientific and technological fields are inspired by phenomena that combine mathematical and artistic qualities. Respectively, several contemporary artists, graphic designers, craftsmen, and craftswomen are fascinated by scientific discoveries, mathematics, and geometry and use the formulas and principles of each in different ways in their artistic and creative work.

Since the birth of civilization, mathematics and art have been essential instruments with which human beings have discerned, constituted, and reflected reality and expressed their attempts to explain, dominate, and control nature (Hadot 2006). Mathematics and art form their own modes of communication and are used to reveal the alleged structures of the universe and nature. They have both long contributed to the practices of illustrating and manifesting the reality both intrinsic and extrinsic to human beings. Both mathematics and arts are conceptual and symbolic 'languages' that humans have used in their attempts to depict their empirical perceptions and visions. Both 'languages' refer to worlds outside their respective symbolic spheres - they each provide representations of visible and non-visible phenomena. The 'languages' of mathematics and art are both based on cultural agreements and their interpretation requires a 'reader' who is able to decode their messages. As Bas C. van Fraassen $(2008,9)$ notes: "The world, the world that our science is of, is the world depicted in science, and what is depicted there, is the content of its theoretical representations [-]." The same can be said of the arts - the world of art is the world depicted in the language of art. 
Arts offer us artistic or emblematic representations of the world. 'Reading' the language of mathematics and art requires knowledge of these 'languages' and competence to decipher their content. Reading and decoding are cultural and human actions - they always take place within a cultural and subjective context. But how well do these two 'languages' communicate with each other?

The history of Western culture from antiquity till the present can primarily be seen as a continuum of epistemological battles and alliances between two interpretations of how to describe the world. According to these views, the world can be grasped through explanations that are either cultural, and thus particular, or scientific, and thus universal. Each discipline argues for who has actually revealed the 'mysteries' of the world, manifesting the human mind and reality, containing truths, and explaining beauty. These two views have formed a dualistic context that has made philosophers, artists, and scientists question whether the world and its diverse phenomena can be explained and perceived through the universal laws of mathematics, or rather as culture-bound narratives and symbols; and whether the world can be best represented using the 'language' of mathematics or that of the arts.

Contemporary linguists have defined different meaning-making modes and distinct strategies and practices of perceiving reality and its phenomena as discourses. Scholars have used the concept of discourse to refer to specific and restricted ways of producing meanings in and through certain kinds of social and cultural practices and uses of language. The concept has also been applied to explain broader societal structures that have had an impact on various domains in societies and which are manifested, in these domains in the similarity of strivings, values, ways of thinking, and the actions of an era (van Dijk 1997). In this broader sense the concept of discourse approaches the idea of an episteme, as discussed by Michel Foucault. For Foucault (1970), certain kinds of configurations of knowledge, as well as underlying assumptions regarding truth, good, and proper, produce the so-called epistemological unconscious of an era, which encompasses not only science, but a wider range of discourses in culture, education, politics, law, morality, etc. Several epistemes may coexist simultaneously and it is their interaction that produces complex power hierarchies and various systems of power-knowledge (Foucault 1980, 194-198). 
Following Foucault's conceptualization, the opposing views of describing the world can be conceived as two distinct epistemes - the culturalemblematic and the mathematical-logical epistemes - in which the nature of knowledge and notions about reality, truth, and beauty are differently comprehended. In both epistemes the use of language - in a broad Barthesian sense (Barthes 1973) - produces its objects. The nature of knowledge, reality, truth, good, and beauty are given meanings in linguistic utterances, textual expressions, and artistic, mathematical, and scientific representations.

Despite their epistemological differences, the epistemes share a common conceptual realm; certain terms, words, and concepts are used within both. This common realm stems from the vocabulary of aesthetics. Mathematicians and scientists often refer to the aesthetic qualities of geometry, mathematical theorems, and scientific discoveries using the terms and expressions artists and art critics employ when evaluating artistic objects and visualizations (Goldstein 2005). The idea of beauty is referred to in the fields of science, mathematics, and arts. The investigation of the uses of language, modes of conceptualization, and discursive meaning-making reveal the epistemological and ontological differences between the cultural-emblematic and the mathematical-logical epistemes. The common objects of interest in science, mathematics, and arts - that is visualizations based on scientific discoveries, mathematical theorems, and geometry-offer an interesting platform for these investigations.

\section{Making Sense of the World in Mathematical-Logical and Cultural- Emblematic Epistemes}

The pre-Socratic philosophers already sought to understand the world through searching for a single universal law that determines the world and structures all its qualities and phenomena. In their view, a universal law gives everything a certain form, and form is closely related to the idea of beauty. Pythagoras was the first philosopher in ancient Greece to unify diverse views on cosmology, mathematics, natural science, and aesthetics into a complete theory. According to his thinking, 'everything' (the entire universe) was based on numbers. After antiquity, Pythagorean tradition continued to influence notions about the fundamental basis of the world. These notions regained popularity during the Renaissance. The Greek and Renaissance notions that tie the structure of the universe together with aesthetics, form the basis of the mathematical-logical episteme. 
In the discourses of the mathematical-logical episteme, geometrical and mathematical principles of visual phenomena relate their aesthetics to the spheres of reason and logic. In general, reason, logic, and the objectivity of perception are determinants that are often related to science (Darvas $2007,375)$ and which can be considered as determining the episteme. In its discourses, the 'language' of geometry and mathematics is deemed universal, and, thus, the images and objects based on them can be considered to 'carry' fundamental universality. In addition, the episteme's discourses relate the universality of geometry and mathematics to the idea of their beauty, and thus come to emphasize the idea of beauty as a universal quality. Since antiquity, mathematicians, scientists, and philosophers have brought to the fore how, for example the facades of architectural masterpieces and the compositions of famous paintings obey the proportions of the Golden Ratio, the Fibonacci sequence, geometrical patterns, or other mathematical sequences. The beauty of such works of art has been located in the geometrical and mathematical principles they follow and which are considered to imply the existence of universal aesthetics.

The fundamental point of departure in the mathematical-logical episteme is in the overall theories and total views of a world based on mathematical principles. This episteme relies on the belief/knowledge of the rationality of the world and its physical phenomena. According to this perspective, the world and its structures are therefore possible to understand, explain, and depict through mathematical theorems and scientific theories. "We live in a universe of patterns", is how Ian Stewart $(1995,1)$ begins his book on mathematics and numbers, which to him are the elements that underlie everything. Besides mathematics, geometry, and numbers in general, several scholars have perceived symmetry as the key to explain the structure, function, and logic of the world and its diverse physical, social, and cultural phenomena (e.g., Rosen 2008; Darvas 2007; Stewart 2007).

As mathematics, geometry, and numbers are often discussed within the episteme as the laws of nature on which the whole world is based, images and objects which obey the laws of geometry and mathematics can at the same time be considered as obeying the natural laws of beauty. Aside from beauty, mathematics, geometry, and symmetry (see particularly Stewart 2007) have been connected to the idea of truth. In the history of philosophical thinking, the search for beauty and truth has often been 
complemented by the search for the good (Darvas 2007, 367). Beauty, truth, and the good form the fundamental trinity which, on the one hand, as Darvas (2007) explains, have been perceived to form the final goal of mathematics, while having, on the other hand, the role of an epiphenomenon: beauty, truth, and the good are taken as by-products of the laws of geometry and mathematics - as universal qualities that follow from the mathematical principles. The trinity of beauty, truth, and the good was brought to the fore already in the dialogues of Plato, and the interest in it has continued throughout the philosophical history of the Western science and arts (Darvas 2007).

In the discourses within the mathematical-logical episteme, the history of Western art can be perceived in and explained by discoveries and inventions in the use of geometry and by mathematics in artistic work. Styles, epochs, and works of art have been discussed as a reinvention of, rethinking of, or return to geometry. The history of Western art has been seen as an evolution of the use of geometrical and mathematical rules developing from the invention of the perspective to modern art in which artistic expression was finally reduced and transformed into the composition of pure geometric forms and solids (see e.g., Darvas 2007; Cucker 2013). The development of computing programs and the possibilities they offer for creating graphic representations of algorithmic processes and various types of digital art and music form the latest phase in this evolution, as Charalampos Saitis describes in his article in this volume. Because the discourses within the mathematical-logical episteme emphasize the universality of geometry and mathematics and the aesthetics related to them, the aesthetics of images and objects based on geometry and mathematics are not considered dependent on the cultural, historical, or individual contexts of their receivers. In the discourses of the episteme, the aesthetics of these images and objects is considered to be non-subjective and non-historical. Their aesthetic value remains throughout history and is accessible within different cultures.

Contrary to the views of the mathematical-logical episteme, images and objects based on geometry and mathematics can be conceived of, understood, and explained as cultural representations and artistic emblems that transmit diverse meanings to different receivers. In particular, scholars in the humanities, such as historians, art historians, ethnologists, anthropologists, and also ethno-mathematicians, have emphasized the cultural, social, and historical contexts both in the production and reception of geometrical and mathematical images. These notions rely on 
the world-view of the cultural-emblematic episteme within which universal laws are not considered to explain the meanings of reality and in which reason and logic are believed to be unable to reveal any fundamental truths. In the discourses within the episteme, different truths are perceived as cultural formations and, thus, historically transforming constructions. In this episteme, mathematical and scientific explanations of the world are also seen as cultural, and ideas such as intrinsic beauty and the universal explanatory power of symmetry, geometrical patterns, and mathematical proportions, such as the Golden Ratio, can also be perceived as cultural constructions (Livio 2003).

Within the cultural-emblematic episteme, notions of beauty and aesthetics are considered to be culturally-bound conceptualizations and experiences based on conventions and shared cultural and social habits produced and learned in and through social and cultural reproduction. Particularly in the fields of art history, cultural history, and art philosophy, ideas about beauty, changes in artistic expressions, aesthetics ideals, and styles have been explained by transforming historical and cultural schemas based on learning and on previous experiences (see e.g., Goodman 1976). In the discourses within each episteme, aesthetic experiences do not have a universal or an objective basis. Instead of reason and objectivity, the discourses of each episteme stress the subjects and their subjective emotions and cultural positions in the reception of images. Instead of the non-sensible, the discourses highlight the emotional and affective nature of images. In the views of the cultural-emblematic episteme, each culture and its historical phase has its own system of knowledge, interpretational frame, and aesthetic ideal, which determine the production, interpretation, and use of images.

In the field of art, aesthetic ideals and definitions of good art have been, and still are, a matter of negotiation and contest. In the field of art, the socalled gate-keepers (acknowledged experts, established art critics, workers in art museums and galleries, art historians, etc.) either intentionally or unintentionally determine and define what is considered to be art, and what kinds of expressions are included in the aesthetic sphere. Agents in the field of art do not unanimously agree on these definitions, rather quite the contrary. Art sociologists, such as Pierre Bourdieu (1984), have emphasized how the fields of art and culture are founded on a continuous battle about meanings and the positions out of which these meanings can be produced. In mathematics, the idea of beauty and aesthetics can also be considered as discursively and socially 
determined. Daniel J. Goldstein $(2005,94)$ states that mathematical beauty and artistic beauty are both cultural constructions. New mathematical theories and artistic innovations become objects of beauty and aesthetic experience only after new generations of experts and practitioners in the fields are educated in them. In both fields, the sensations of aesthetics require familiarity with the 'language' and conventions of the field, which is gained over time through effort and exercise (Goldstein 2005; Rota 2008, 128).

The mathematical-logical and cultural-emblematic epistemes and their different modes of explaining the world and its phenomena can be described as being opposite to each other. Similarly, the fields of science and the arts are often considered to be two incompatible modes of 'grasping' the world; they are split into objective and subjective, theoretical and practical, and perceived as appealing to either reason or the emotions. However, throughout history these two modes have been intertwined in various ways. Since antiquity, several scholars and artists have fruitfully sought to merge these modes and create interdisciplinary explanations of the world by combining the views of the two epistemes in their thinking. The interdependence and interaction between the culturalemblematic and the mathematical-logical world views culminated with Renaissance scholarship, theoretical treatises, and artistic praxes. During the Renaissance, geometry and mathematical proportions were adopted as underlying principles e.g., in perspective theory, architectural concepts, definitions of musical harmonies, and ideals of bodily beauty. Several scholars have discussed and highlighted the continuity of the affinity between the mathematical and artistic ethos in the Western world from the Renaissance to the emergence of modernism in the end of the nineteenth century (Kemp 1990).

However, in academic and scholarly practices the cultural-emblematic and mathematical-logical epistemes can also be interpreted as gradually diverging following the Renaissance. The development of modern science and academia through distinguished scholarship had an impact on the specialization of disciplines and the deepening particularization of each field of inquiry. As a consequence, the core questions, methods, and epistemological and ontological understanding in different disciplines were distinguished and the interaction and dialogue between them narrowed. Similarly, art developed into its own field with its own criteria of evaluation, special value systems, expertise, and connoisseurship. The field of art, its agents, praxes, and knowledge was institutionalized as a 
hierarchical system. Because of this, acting in the realm of the arts required and still requires a special competence and an acknowledged position within its hierarchy. In addition to emphasizing the affinity of science, mathematics, geometry, arts, and aesthetics in the Western world, the relations of the cultural-emblematic and the mathematical-logical epistemes can be thus presented as a collision or a dis-encounter. On the one hand, the differences between the epistemes have caused disinterest in the world views and modes of thinking of the other episteme. On the other hand, the agents in science and the arts have fostered epistemic thinking in their own disciplines, and, thus, created even stronger differences and confrontations between the epistemes.

Throughout the past decades, multidisciplinary, cross- and transdisciplinary, and interdisciplinary approaches have been emphasized in the natural, social, and human sciences. The recent developments in academia have aimed at producing new bridges between the culturalemblematic and the mathematical-logical epistemes. Along with the recent development and innovations in science, technology, and the digital world, we are facing a variety of new possibilities strengthening the interaction between the epistemes and producing a deeper understanding and co-operation between the experts interested in the interdisciplinary discussions between science, mathematics, and art.

\section{Opening New Views to Interdisciplinarity Through Aesthetics}

Science and technology are not only subjects of functional rationality, but like any other social objects and cultural artefacts, they have hermeneutically interpretable dimensions that can be perceived as their social meaning and cultural horizon. The social meaning, cultural horizon, and functional rationality are intertwined: the scientific and technological phenomena can be interpreted as embodying complexity, which includes aesthetic characteristics as well. Scientific discoveries, inventions, innovations, experiments, observations, models, systems, and simulations often become the objects of aesthetical interpretation and experience, and their aesthetic dimensions are exposed by multifaceted approaches and interdisciplinary conceptions used in their meaningmaking processes. For example, scientific models not only have informative and cognitive values but symbolic, iconic, or even psychological meanings. As creative and 'fictive' representations of reality and its diverse phenomena, scientific models can be examined also as results of complex socio-cultural experiences (Feenberg 2010), 
including elements that can also be perceived within the aesthetic framework.

Throughout the history of science, the aesthetic dimension has stimulated the development of scientific and technological innovations: artworks, art history, and theories in aesthetics have provided sources of inspiration, conceptual tools, and even research material for science. This reciprocity of disciplines has not occurred in a scientific or artistic vacuum, but it rather is an interdisciplinary outgrowth of the natural interaction between arts, mathematics, and science (Henderson 2013), practiced by the scientists, mathematicians, and artists themselves.

What is the role of aesthetic dimensions in contemporary scientific discoveries, and what is the role of science in contemporary art? While the specific relationship between science and art has recently been studied from various aspects, we still lack a common theoretical ground that we could call the aesthetics of interdisciplinarity - an approach that would provide a deeper understanding of the following chiasmatic relations:

- scientific representations, models, and simulations as an artwork $<>$ artworks as a scientific representation, model, or simulation;

- implementation of scientific and technological tools and concepts during the creation of art $<>$ implementation of artistic creativity and inspiration during the scientific work;

- communicating aesthetic experiences with the tools of science and technology $<>$ communicating scientific, technological content through the artistic creation;

- a same object as a modeling kit, a toy, and material for artistic creation;

- a creation of patterns and algorithms as games $<>$ creating art with the implementation of patterns and algorithms;

- useful, playful, and creative dimensions of a scientific object.

Along with the discussions in this volume we aim to offer a conceptual framework that combines the different perspectives of science, mathematics, and art, and to unite these perspectives into a third 
conception - the aesthetics of interdisciplinarity. The aim is to develop a scientifically interesting and artistically inspiring new framework of research, which can function as a fruitful interdisciplinary discourse on the aesthetic aspects of scientific objects and the scientific aspects of aesthetic artefacts. With this conception of the aesthetics of interdisciplinarity we aim to surpass the discursive duality of the mathematical-logical and cultural-emblematic epistemes in grasping the world, and to emphasize instead the significance of perceiving and making sense of the world by accepting the interdependence and interplay of aspects in this interdisciplinary field.

More than half of the articles in this volume evolved from papers presented in the course of the Bridges conference series. The authors of these papers (Schattschneider, Jablan-Radović, Saitis, Washburn-Crowe, Gerdes, Vierling-Claassen, Moody, Orosz, Voss-Andreae, and Kelle) have subsequently adapted and expanded their work for publication in this volume. It is precisely the research discussed in these studies that convinced the editors to rethink how interdisciplinarity is related to the field of aesthetics. To provide even a broader examination of the nexuses joining interdisciplinarity to aesthetics, several other scholars (Cohen, Usvamaa-Routila, Gelfert, Darvas, Kähkönen, and Lähdesmäki) was invited to contribute to the volume. The discussion of the aesthetics of interdisciplinarity in this volume can be seen as a continuation of the lively dialogue between mathematics and art and their connection to culture, art theory, and education that has consistently taken place during the Bridges conferences.

Since 2017 marks the twentieth anniversary of the Bridges conferences, this volume was compiled with the goal of utilizing and selecting articles from the more than 8000 pages of material contained in the Bridges archive. ${ }^{1}$ Ultimately, the editors' aim was to take the results stemming from research in mathematics in particular and render them available to experts in cultural studies and art theory, while also providing a selection of international examples of mathematical art-visualizations based on diverse scientific discoveries, mathematical formulas, and geometry-for readers' perusal. For students interested in cultural studies, art theory, and art education, this volume serves as an introduction to the vast common ground stretching between mathematics and art.

As a reflection of the great debt our volume owes Bridges conferences, we consider important to offer a brief overview of the history of the Bridges 
community. This overview reveals how Bridges was founded on a primarily mathematics-based experiment in establishing an ongoing conversation between mathematics and art. In the course of the past two decades, numerous outcomes originating from this dialogue strongly suggest that examinations in cultural studies or art theory cannot be complete without taking the field of mathematics into consideration. At the same time, the demand to become more familiar with, as well as explore, the cultural and artistic possibilities inherent in mathematics has palpably grown within the mathematics community itself. In this respect, the aesthetics of interdisciplinarity and the development of an interdisciplinary aesthetics provides a means of establishing a platform that joins a) cultural studies and art theory that is steeped in a knowledge and awareness of mathematics; b) mathematical examination of artistic and cultural phenomena; c) educational practices; and d) artistic production itself.

Furthermore, our attempt to look back at the history of the Bridges community is motivated by a personal and intellectual loss the Bridges and international math-art community has recently faced. In the beginning of July, 2016, just a few months before the closing of this volume as well as the Bridges Finland Conference held at the University of Jyväskylä, the founder of the Bridges community, Reza Sarhangi, unexpectedly passed away. This volume is therefore intended as a token of respect to the memory of Reza Sarhangi and the intellectual legacy that this volume will hopefully pass on to a wider audience. With this volume the editors would also like to remember the pioneer in ethnomathematics, Paulus Gerdes, who died in 2014, and Slavik Jablan, the distinguished researcher of visual mathematics, knot theory and inspired mathematic artist, who passed away in 2015. These three researchers were not only internationally recognized scholars, but also extremely influential educators who devoted great energy to attaining exemplary results in teacher education while simultaneously spreading knowledge in science and art to wider audiences. The editors of this volume wish that the touchstones Sarhangi, Jablan, and Gerdes laid out in their work, will offer a source of inspiration for researchers of art history, cultural studies and education. It is with this goal in mind that we hope this volume will also prove useful to instructors in teacher education as well.

History, Organization, and Conferences of the Bridges Community 
The Bridges conferences were started by Reza Sarhangi in 1998, and the first few meetings were hosted by Southwestern College in Winfield, Kansas, USA. Sarhangi emigrated to the United States from Iran in 1986. Sarhangi's broad range of personal interests (Shrestha 2016) as well as his research into ancient Persia's mathematical and artistic past helped him to direct attention to mathematics' complex cultural roots. For his integrational approach to mathematics and art, Sarhangi looked far beyond the well-known works of artists in mathematical art, such as M. C. Escher (Sarhangi and Martin 1998) and explored in particular the medieval period of Persian history, ${ }^{2}$ when mathematics, arts and crafts coexisted side-by-side. Sarhangi had studied and continuously emphasized as a great example the work of Abul Wafa al-Buzjani (940-997/998), one of the most renowned mathematicians of his time. Al-Buzjani's treatise, On Those Parts of Geometry Needed by Craftsmen, was written to educate craftspeople in geometry. For medieval craftspeople, creating the decorative motifs common to the Persian art of that era demanded not only continuous training, but also regular consultation with mathematicians. For example, decorating the inner as well as outer spherical surface of cupolas with tiles featuring highly regular, yet still extremely complex geometric patterns would have required advanced knowledge of geometry. The sophisticated, mathematical nature of Persian decorative arts not only makes them interesting from a historical perspective, but also provides a fascinating area of research for mathematicians today (Lu and Steinhardt 2007).

Before emigrating to the United States, Sarhangi was more than a teacher of mathematics interested in Persian traditions. He was a graphic artist, teacher of drama, playwright, theatre director, and props designer. When added to his background in mathematics and history, his first-hand experience of complex and collective artistic processes - such as creating and performing a play-gave him deep insight into the equally complex processes involved in designing and producing medieval Persian tilings. Sarhangi made great use of his many areas of expertise, first as an innovative, young university professor open to new experiments, then later on as an educator of future mathematics teachers. As department chair of Southwestern College's Department of Mathematics, he already introduced creative study modules and theatrical plays on mathematics to change how mathematicians were educated.

In his new country Sarhangi searched for an academic community capable of supporting his broad range of interests. In the early 1990s, the college 
implemented a new Integrative Studies Program that drew together faculty from all other traditional and professional programs. As director of the Integrative Studies Program, Daniel F. Daniel, Sarhangi's close friend and mentor at Southwestern College, suggested that Sarhangi would establish a new course for this program. His course on the connections between mathematics and the arts became very popular among students. Sarhangi also attended the Art and Mathematics (AM) conferences organized by Nat Friedman at the State University of New York at Albany from 1992 to 1998. The AM conferences gathered artists, architects, and other experts applying mathematics creatively. The spirit of cooperation engendered by these AM gatherings led to the publication of several interdisciplinary papers uniting different perspectives to form a kaleidoscope-like vision of the given topic. Sarhangi felt he was witnessing the rebirth of a long-forgotten paradigm from Abul Wafa alBuzjani's time. He could see first-hand how a new form of art araised from the dialogue between the mathematician creating theories for solving complex artistic and architectural problems, and the master putting theories into practice. This art possesses a unique, aesthetic quality all its own, whose analysis demands a new approach, which we can call interdisciplinary aesthetics, because it is both mathematical and artistic in nature. ${ }^{4}$

Known as ISAMA (International Society of the Arts, Mathematics, and Architecture $)^{5}$ as of 1998, the AM movement was the direct, American antecedent to the later Bridges conferences. Indeed, three of Bridges' first four directors: George Hart, ${ }^{6}$ Carlo Séquin ${ }^{7}$, and Reza Sarhangi were ISAMA veterans. The fourth director, Craig S. Kaplan', started his career in mathematical art in 1999 after joining the ISAMA and Bridges communities and co-organizing the MOSAIC 2000 conference, which examined connections between computer programming and the arts. Robert W. Fathauer ${ }^{9}$ soon assumed responsibility for organizing the Bridges art exhibits. ${ }^{10}$

Many groups and "schools" have connected to form the background for the American, European, and Asian science and art communities currently involved in the Bridges community. These include the Mathematics and Culture conferences (Emmer 2004-2012, 2012-2014, 2015), the Nexus conferences $^{11}$, and the Symmetry Festivals ${ }^{12}$ started by György Darvas and Dénes Nagy in 1989 in Budapest, Hungary. The increasingly active presence of the European Society of Mathematics and Arts $^{13}$ also deserves mention. Bridges also enjoys a close-knit relationship with the 
International Mathematics \& Design Association located in Buenos Aires, established by the mathematician Vera W. de Spinadel, in 1998. The Mathematical Association of America's Special Interest Group on Mathematics and the Arts (SIGMAA-ARTS) was established by Bridges members and participants, and currently has more than 200 members. ${ }^{14}$ Barely 60 participants attended the first Bridges conferences. Today they attract annually around 300-400 conference participants from around the globe and thousands of audience members. Bridges conferences have been held in Winfield, USA (1998-2001); Towson, USA (2002); Granada, Spain (2003); Winfield, USA (2004); Banff, Canada (2005); London, UK (2006); San Sebastian, Spain (2007); Leeuwarden, The Netherlands (2008); Banff, Canada (2009); Pécs, Hungary (2010); Coimbra, Portugal (2011); Towson, USA (2012); Enschede, The Netherlands (2013); Seoul, Korea (2014); Baltimore, USA (2015); Jyväskylä, Finland (2016); Waterloo, Canada (2017).

Today Bridges conferences enjoy wide recognition from around the globe. Both leading media sources and scientific circles regularly report on Bridges events. The multi-faceted nature of these events offers a likely explanation for this circumstance: the sheer diversity of topics and areas addressed understandably attracts a diverse audience of scholars and artists. In addition to mathematicians, scientists, art scholars, and education experts, Bridges conferences attract painters, musicians, architects, literary scholars, computer programmers, sculptors, dancers, craftspeople, model builders, etc.

In accordance with its highly diverse audience, the aims of each conference reflect many different aspects. Bridges always places great emphasis on providing opportunities for approaches that both innovate and integrate, thereby emphasizing the importance of interdisciplinary cooperation in the research of mathematics and the arts. It presents a platform for scholars, teachers, and artists intent upon surpassing boundaries while also exchanging their own experiences. In addition to supplying professional support, it encourages mathematics teachers to utilize creative, artistic processes and tools in passing on mathematical knowledge, and art teachers to reveal the mathematics involved in diverse artistic processes.

Like musical interludes and concerts included in the Bridges program, intense workshop projects are conducted with the purpose of analyzing the practical application of given topics, and these have formed an 
integral part of the conference. The educational relevance of math-art approaches has been demonstrated in interactive, experience-oriented workshops since Bridges' early days. The conference emphasizes active participation: mathematical artworks are put on display in Bridges' mathart exhibits, rather than simply being discussed in conference lectures. The Bridges exhibit has since grown to be the largest exhibit of mathematical-art in the world. Since its inception, creative programs have become increasingly structured and have now evolved into separate areas of expertise directed by skilled professionals.

The following key elements form the backbone of Bridges conferences: Plenary lectures-organized in a joint effort by the members of the Bridges Organization's Board of Directors ${ }^{15}$ as well as the local academic coordinators. Visitors to Bridges events can personally meet internationally celebrated members of the scientific world, such as mathematician Harold S. M. Coxeter, physicist John C. Mather, and chemist Sir Harold Kroto, both recipients of the Nobel Prize. Ernő Rubik, inventor of the Rubik's Cube, and László Lovász, chosen for the Wolf Prize, have presented their concepts at Bridges. The Fields Medal-laureate Cédric Villani has contributed his expertise to Bridges. The presence of Ingrid Daubechies, the first female president of the International Mathematics Union, also deserves a mention. John H. Conway, founder of the theory for cell automation, Alan C. Kay, the revolutionary developer of personal computers and programming, Marjorie W. Senechal as many others have numbered among past Bridges plenary speakers. As a part of the plenary addresses, lectures related to the host location or country highlight those significant contributions in math-art achieved locally.

Section lectures-selected and reviewed anonymously by the Bridges Organization's roughly 60-member program committee, out of proposed papers sent in response to the conference's open call. The program committee's work is directed by members responsible for editing the annual conference volume, a project headed by different people each year. Workshops - selected and reviewed among all workshop papers sent in response to the program committee's open call. The committee for workshop papers as of 2015 to this day has been directed by Kristóf Fenyvesi. The interactive nature of these workshops familiarizes participants with different kinds of math-art applications and content, much of which can be utilized in education. Started by Mara Alagic and Paul Gailiunas, the workshop series, Bridges for Teachers-Teachers for 
Bridges, deserves a mention due to its attention to the development, interactive testing, and joint evaluation of educational applications. Bridges Mathematics and Art Short Movie Festival-the program of which is compiled by Nathan and Amy Selikoff, as well as by a selection panel led by Robert Bosch and comprising many representatives from various artistic and scientific fields.

The Mathematical Art Exhibit-in recent years displaying works by more than 100 artists from over 30 countries, thereby earning its title as the world's single largest exhibit of math-art. The exhibit's leading curator is the former NASA researcher, tessellation expert and math-artist, Robert W. Fathauer, who leads the interdisciplinary selection committee responsible for choosing exhibit works. Of the many artists whose work has been shown at Bridges exhibits, Brent Collins deserves a special mention. Collins not only supported this event from its very inception, he also created Genesis, a Möbius-like loop that came to be used as the logo of the Bridges Organization. All works shown at the exhibit are featured in a full color album.

The Mathematical Theatre Show-performance of a play which explores connections between art and science. As of 2009, Steve Abbott not only leads this event, but also stages new works every year, performed by conference participants who volunteer to be a part of his theatrical troupe. Occasionally, these performances also include dancing. Directed by mathematician and dancer Karl Schaffer and dancer Erik Stern, the Schaffer and Stern Dance Ensemble has performed multiple times at Bridges, similar to Mime-Matics, the mime group created by the mathematicians Tim and Tanya Chartier. Music Night - a program frequently featuring the debut of new compositions in mathematical-music. A tradition begun by the musician and mathematician Corey Cerovsek, and after him the baton for Bridges music nights has been passed on to Princeton University's musicologist, Dmitri Tymoczko. Music Night programs have included Bach interpretations by Harvard's mathematician, pianist and chess master, Noam Elkies, as well as works by contemporary composers such as Fernando Benadon, Clifton Callender, or Adrian Childs. In addition to musical programs featuring professional musicians, the informal music nights performed by music-loving conference participants is at least as important Bridges tradition-begun by internationally renowned math popularizer and musician Vi Hart.

Poetry Afternoon-an event organized by the mathematician and poet Sarah Glaz, who introduces the audience to the international scene of mathematical-poetry. 
Family/Public Day-one of the conference's most essential elements which provides the Bridges community with the opportunity to showcase its scientific and artistic work in front of a lay audience. For no entrance fee, workshops for building giant models and other activities are staged for both adults and children alike. As of 2010, this day has been organized by Kristóf Fenyvesi.

Public Event-is open to the entire audience and not only to professional conference participants and provides an opportunity for the introduction of interesting artistic and scientific projects in the form of presentations, videos, and live on-stage demonstrations.

Due to the wide-ranging nature of its programs, Bridges not only promotes new achievements in the area of mathematical art, but it also allows the seemingly distant worlds of academics and the artists to spread their message among a much broader audience. All plenary and section lectures, as well as workshop descriptions are published in a richly illustrated, massive volume of conference materials frequently 600 or more pages in length, yet available free-of-charge on the Bridges website.

\section{Content of the Volume}

The aim of this volume is to contribute to the bridge building efforts between cultural and art studies and the mathematical domain of knowledge by exploring interdisciplinary approaches to the aesthetics of mathematical art. The authors of the volume approach their topics from the point of view of aesthetics, anthropology, art history, art theory, artistic practice, ethno-mathematics, geometry, mathematics, philosophy, physics, study of visual illusions, and symmetry studies. The selection of articles in the volume is based on their interdisciplinary nature, their accessibility for a large scientific audience, and their contribution to broaden the views on the role of aesthetics in the confluence of science, mathematics, culture, and art. The volume contains four thematic parts.

Part I, entitled 'Bridging Art and Mathematics: Concepts, Theories, and Philosophies' provides theoretical, conceptual, and philosophical insights on the main topic of the volume. The section includes four articles in which mathematics, geometry, art, design, and visuality are approached as cognitive phenomena and as intertwined to each other in various ways exceeding the borders of separate scientific disciplines. Interfaces of these phenomena form a favorable ground for theoretical and philosophical discussions on sensation, perception, conceptualization, understanding, 
creativity, imagination, and imaging. Although the articles in the section explore the similarities and differences of mathematical and artistic thinking and production of knowledge from an interdisciplinary point of view, each article takes to the topic a particular approach through which the relations between arts and mathematics are discussed. These approaches include: discussions on dimensions and transformations in the philosophies of science; theorizations of image and percept; exploring the discourses and conceptualizations of beauty and aesthetics; and applying symmetry studies. Philosophical discussions in the articles is strengthened particularly from the point of view of phenomenology.

Mark Daniel Cohen's article discusses the relationship between science and visual art by focusing on transformations in the history of the philosophy of science. The starting point of the article is in the conception of truth. As Cohen notes, both science and art can be considered as pursuits of truth, however, differing in their notions of it. Cohen discusses the epistemological questions in the production of knowledge and understanding of the real, and the contradiction between objectivity and subjectivity in the points of view and practices of science and art. For him, the contradictions between science and art result from the clash between the Newtonian worldview and the empiricist paradigm of the philosophy of science, i.e., the question of the role of human senses, perception, and observation in the production of knowledge of the real. As Cohen writes, mathematics is central to the Newtonian worldview, while anthropomorphic and art-influenced world view form a core in the empiric perceptual science. Cohen takes Goethe's thinking as an example of the perceptual point of view to the real. Since Goethe's time, the ideas of perception of the real and the investigation of the truth in science and art have alienated. However, the ways of conceptualizing the real and the truth in mathematics and arts were approached at a new way in the beginning of the twentieth century. Cohen notes how developments in mathematics (such as the non-Euclidean geometry) shifted the interests of the discipline to the areas in which the investigated situations were impossible to be formed as sensory experiences - they were imperceptible. Similar trajectories can be found in the transformation of art at the beginning of the twentieth century: in various Modern art movements, artists aimed to visually reveal the truth that was, however, considered non-visualizable. Both disciplines shared an interest to nonvisible, imperceptible, and even to non-imaginable worlds. 
In her article Sirkkaliisa Usvamaa-Routila discusses architecture as a visible phenomenon. If mathematical properties, such as proportions, are assumed to be capable of arousing aesthetic experiences, they are also bound to an assumption that they are in one way or another seen, not only imagined. However, Usvamaa-Routila brings to the discussion the role of imagination and the importance of will in the aesthetic experience. Usvamaa-Routila's starting point is the notion of how visual implication aids dealing with specific problems: How can we see properties that cannot be visually apprehended? This problem was discussed, e.g., by Le Corbusier, who used the term linee occulte to describe all the lines of a building that cannot be seen, but which are most significant to the successful architectural design. Usvamaa-Routila continues this discussion by suggesting that properties that are exhibited and seen in an architectural work of art "visually implicate" properties that are not seen, although they are experienced. We may assume that for instance the corners of a window visually implicate the diagonals, although these are not exhibited and therefore cannot be seen in the proper sense of perception. We may therefore assume that they are seen only mentally, by implication only. This means that our aesthetic perceptions may be affected by our imagination. In her article, Usvamaa-Routila discusses the dimensions of visual implication through Husserl's phenomenology and Sartre's observations of the interplay of perception and imagination.

Axel Gelfert's article focuses on the confluences of art and mathematics, and introduces ways in which mathematics has attracted the attention of artists since the Renaissance. The notion that mathematical objects, such as proofs or theorems, can have an aesthetic value has long had some currency among mathematicians and philosophers of mathematics. As Gelfert notes, in popular discussions of mathematics, it is common to come across references to the perceived beauty of a theorem, or the superior elegance of one proof as compared with another. However, the invocations of mathematical beauty, its source, and cognitive function are surrounded "an air of mystery", as Gelfert notes, and such aesthetic judgments often require a considerable degree of familiarity with mathematics itself. In the philosophy of science and mathematics, this debate has a parallel in discussions, sparked by Eugene Wigner's article, about "the unreasonable effectiveness of mathematics in the natural sciences". Gelfert's article discusses the crossing of these two debates by exploring the appeal that the aesthetic dimension of mathematics has had on artists and scientists alike. The article contributes to the philosophical 
discussion on these topics through introducing various empirical examples ranging from the sciences to the arts.

György Darvas discusses in his article interdisciplinary applications of the symmetry phenomena. He introduces the basic terms and geometric appearances of symmetry (e.g., mirror reflection, rotation, translation, and similitude), and how they appear in decorative arts. Symmetry operations in the decorative arts can be presented in one dimension (frieze patterns), in two dimensions (wallpapers or tiling), in three dimensions (crystals), and extended to cover surfaces (spheres and polyhedra). The article indicates how symmetry studies have been used in determining and understanding the world and its basic substance since ancient Greece. In the ancient times, symmetry was connected to the theories on primary elements, cosmological explanations, the movement of planets, and the harmony of numbers and their equivalences, e.g., to music and various phenomena in nature. As an example of the interrelation of diverse symmetry phenomena, Darvas discusses proportion theories, Golden section, Fibonacci sequence, Platonic solids, and their geometric applications. The article provides examples of how the aesthetically pleasing proportions and shapes are embodied not only in artworks, but also applied in recent scientific achievements, such as in quasi-crystals, new molecules (such as the fullerene and the graphene-that are important to nanoscience), and particle physics. In general, the article demonstrates the productivity of interdisciplinarity for science-art relationship.

Part II, entitled 'Studying Mathematical Principles of Composition', includes five articles which explore patterns, designs, and images by explaining their geometric and mathematical principles and logic. Since ancient times, craftsmen, craftswomen, artists, and designers have created patterns and images based on geometry or mathematical sequences. These patterns and images have intrigued various scholars in the fields of mathematics, art history, cultural studies, and ethnology. In different disciplines geometric patterns and images are approached in different ways by emphasizing e.g., their mathematic structures, art historical development, or cultural historical meanings. New points of view to these visual phenomena enrich the understanding of them. Geometry and mathematics based patterns, designs, and images include multilayered information and meanings. Recognizing or investigating only one layer of their character narrows the understanding of their diversity, flexibility, and interrelatedness as interdisciplinary phenomena. Multi- and interdisciplinary points of view are thus needed in the investigation of 
these patterns and images. The first two articles in the section focus on artists M. C. Escher and Victor Vasarely who are famous for their artworks which contain various geometric puzzles and visual illusions, paradoxes, and problems. The third article introduces the logic of fractals, which are often considered to be a fundamental link between mathematics, art, nature, and aesthetics. The section ends with articles that approach geometrical patterns by combining points of view from ethno-mathematics and history. This kind of interdisciplinary approach to cultural history of ethnic communities or ancient civilizations may renew our understanding of human interaction, communication, and cultural meaning-making processes.

In her article, Doris Schattschneider discusses the works of art of Dutch graphic artist M. C. Escher (1898-1972), who carried out mathematical investigations that led to symmetry drawings of three distinct kinds of tiling with two colors. Escher used several of these drawings as key elements in his prints that further expressed ideas of duality.

Schattschneider analyses Escher's art works by investigating in detail their use of color, tiles, forms, symmetry composition, and tiling principles. In addition, she introduces Escher's working methods and sources of inspiration, which led to new artistic discoveries in his dualitysymmetry studies. Escher's discoveries are demonstrated in the article with numerous illustrations.

Slavik Jablan and Ljiljana Radović investigate in their article Victor Vasarely's (1906-1997) artworks from the point of view of the theory of visual perception, mathematics, and modularity. The authors introduce art movements, Op Art in particular, which form the artistic context to the Vasarely's works. The article indicates that almost all construction methods of composition, modular elements, optical effects, and visual illusions used in Vasarely's works were mostly (re)discovered by him through intuition, creative visual thinking, and experimenting. Jablan and Radović discuss the artist's altering visual means through rich illustrations from different decades in Vasarely's oeuvre.

Charalampos Saitis discusses in his article the world of fractals and their definition and appearance in the arts and nature. In general, understanding nature has always been a reference point for both arts and science. Several aesthetes have put nature at the forefront of artistic achievement: artworks have been expected to represent and manifest nature. Science has likewise been trying to explain the laws that determine nature. As Saitis notes, 
technology has provided both fields with the appropriate tools to deal with their common goal. After Benoit Mandelbrot formulated his findings in non-linear dynamical systems into a theory of fractals, a broad artistic interest exfoliated, resulting in a new form of digital art. Fractal images and music, and the application of the principles of fractal theory in the study of various natural phenomena, became popular among the artists and scientists. Saitis indicates how fractals stand right at the heart of the art-science-technology triangle. The article examines the new perspectives brought into art by fractal geometry and chaos theory, and how the study of the fractal character of nature offers possibilities towards theorizing art.

Dorothy K. Washburn and Donald W. Crowe's article focuses on the pattern symmetries of cultural artifacts by providing systematic descriptions of the investigated patterns to allow the comparison of them between different geographical areas and historical periods. In general, culturally produced patterns can be described in many ways, each useful for different purposes. The article discusses how in early pattern studies, designers of textiles and wallpapers created classificatory groupings that were descriptively idiosyncratic and grouped patterns by motif similarities that were very different in their symmetrical arrangements. With a reference to several recent studies, the article illustrates how a grouping by symmetry rather than a motif similarity reveals new insights to the study of cultural objects and activities. As the article indicates, systematic analysis on the continuities, changes, and use of preferential symmetry can enhance the understanding and interpretation of material objects and cultural information that is embodied in their decorations. Washburn and Crowe illustrate this enhancing of understanding through two different cases: Greek Neolithic pottery decoration and basket decoration of Native-American tribes.

In his article, Paulus Gerdes introduces his fieldwork research about a village called Palmeira in Mozambique. Gerdes has investigated for decades mathematical and geometric patterns in mats and baskets weaved by the local people in the region. An important role of ethno-mathematics is to initiate the recognition of the mathematical ideas of peoples who are rarely referred to in books on the history of mathematics. In such scientific studies, the individuality of the local craftsmen and craftswomen is however often forgotten. In them, the weavers and decorators of handicrafts often remain anonymous. Gerdes's article makes an exception to this tradition by giving a face to a local basket weaver 
master Arlindo Bendzane. In his article, Gerdes introduces various Bendzane's pattern inventions.

Part III, entitled 'Cultural Meanings of Geometric Composition, Structure, and Form', explores geometry-based visual art by discussing the cultural, historical, artistic, and conceptual contexts in which these works of art are created and in which they gain their meanings. Geometry has various functions in the field of visual arts: it has offered a source of inspiration to various periods and stylistic movements; it has served as a tool in the development of designs and ornaments; it is used in the analysis and interpretation of works of art; and the artists use it as an effect and a method in artistic practice. Even though geometry is based on universal mathematical principles and rules, the geometrical patterns as such include various cultural and artistic meanings, which resonate the historical, societal, and cultural conditions of the time of their creation. In Western cultural history, abstract art has often been situated at the intersection of art, geometry, mathematics, and engineering. The emergence of various abstract art movements in the beginning of the twentieth century have been seen as an attempt to bring artistic and scientific thinking closer to each other in a new way. Besides Western abstract art, this section brings to the discussion geometrical principles in old Indian art and Arabic decorations and ornaments, which are often considered as fundamental examples of junctions of artistic practice and geometry. In general, the section emphasizes the contextual understanding of geometry based art: the points of view from the history of science, art history, cultural history, sociology, and anthropology are utilized in attempts of explaining the cultural meanings of geometrical designs and artworks.

Angela Vierling-Claassen's article focuses on the development and construction of models of algebraic curves and mathematical surfaces for scientific and educational purposes and their influence on artistic movements at the beginning of the twentieth century. The article gives a historical overview of the scientific aims and interests in the field of mathematics at the end of the nineteenth century and at the start of the twentieth century when several scholars started to produce models of mathematical surfaces out of plaster, wire, and other materials. These models were used in university instruction to illustrate research and scientific findings. Gradually, mathematical interest in these models faded, but the models themselves were stored and displayed in universities and museums. Vierling-Claassen indicates how the models 
were discovered by several artists from the movements of abstract art. Particularly artists in constructivist and surrealist movements drew inspiration from the models of surfaces. The article brings to the fore the concrete paths of influences and inspiration between mathematics, science, and art.

Satu Kähkönen's article discusses the concept of ornament and the ornament and decoration's problematic relation in the Western world during the nineteenth and twentieth centuries. Decoration and ornament have often been considered as counterparts to modernism, which aimed at the simplification of design. Thus several modernist theoreticians have stressed the grid as an emblem of modernity. Kähkönen indicates how discussions on ornament include various cultural and historical meanings which have influenced the design, use, and interpretation of them in the Western world, particularly in Western architecture. However, the idea of ornament has a profoundly different role and meaning in the Arabic world. In contrast to the development of ornament in the Western world, in Arabic ornamental design, geometrical grids function as starting points of decorations. While in Western architecture, ornament has been seen as a secondary element compared to form or structure, in Arabic architecture, ornament has been considered an inseparable part and a fundamental element of buildings. How do the different conceptualizations of ornament encountered in the contemporary globalized world? Kähkönen discusses these encounters through contemporary modernist architecture used in Islamic cultural centers in Europe. In them, the idea of the grid as a starting point and the end of ornament merges.

In his article, Robert V. Moody discusses Swiss artist Alice Boner (18891981), who lived and worked in India for 40 years. Boner's passion was the old temple cave sculptures and reliefs dating from the sixth to ninth centuries and which appeared in a number of sites around India. During her decades in India, Boner drew numerous sketches of temple sculptures and wrote a diary about her artistic discoveries. In his article, Moody follows Boner's artistic studies by interpreting her diary remarks, which offer insights into the creative artistic process, Boner's struggles and doubts in her work, and the passions that led her to the discoveries about the geometrical underpinnings of Indian temple cave art. The discovery was unexpected: unlike in Arabic art or various periods in Western art, there was no previous evidence of any formal underlying geometrical principles in old Indian art. At the end of his article, Moody explores 
Boner's own artworks wherein she varied the traditional motives and geometrical structure of Indian art. The findings of geometrical design principles in ancient temple art influenced the design of composition in Boner's own artistic production.

In Part IV, entitled 'Geometry, Mathematics, and Science in Artistic Practice', contemporary artists introduce in their own words the theoretical and conceptual background of their works in which they utilize geometry, mathematics, and science in different ways. Making a work of art is a creative process, that includes planning, thinking, experimenting, testing, and structuring. In a creative process, subjective sensations, experiences, inspiration, and intuition are taken as working instruments. The very same instruments are crucial in the creation of artworks based on geometry, mathematics, and science, although these disciplines usually invoke impressions of intellectuality, reason, and, knowledge. The section reveals the multifaceted creative process in artistic work, in which the sources of inspiration vary from literature to quantum physics. All the three artists contributing to this section are very familiar with the geometrical, optical, mathematical, technological, and physical phenomena that are part of the focus of their artistic work. The artistic study of these phenomena demands taking into account ideas of perception, imagination, seeing, viewing, and interaction. As the section indicates, the common element in a creative process is the attitude towards experimenting: the creation of art approaches that of play, in which the function of the imagination is crucial. The section ends with an art historical discussion on the reception and interpretation of public artworks using geometry as their basis and as a source of inspiration.

Hungarian artist István Orosz discusses in his article his literary sources of inspiration-Shakespeare, Poe and Verne-and describes how he depicts the world of their texts through double pictures by using techniques usually associated with Renaissance and Mannerist art. Besides interpreting the writer's texts, Orosz's artworks aim to encode hidden anamorphic portraits of the writers revealed only by viewing them in a special way. Orosz have been making experiments with anamorphosis since the 1970s attempting not only to resurrect anamorphic art but to improve and further develop this old method of composing images. In anamorphosis unrecognizably distorted images become visible from a special view point or via an object, which mirrors the surface of the image when placed on it. In his article, Orosz explains through his own works and sketches how the anamorphic images are planned, outlined, and 
implemented. An understanding of geometry and perspective are the core elements in creating anamorphosis. Orosz emphasizes, however, that intuition, inspiration, and the "inexplicable" will always have a role in a creative work.

Julian Voss-Andreae, a German-born sculptor with a background in physics, introduces in his article his works of art which are inspired by ideas, images, and experiments from quantum physics and its philosophical implications. Voss-Andreae argues that art can indicate aspects of reality that science cannot, and therefore it has the potential to liberate us from the deep impact which the paradigm of classical physics continues to have on our every perception of reality. The ability of art to transcend the literal representation and the function of illustrating only the perceived world enables the artworks to mediate deeper aspects of reality that are hidden to the human eye. In the article, Voss-Andreae describes in detail how his studies and scientific theories and experiments in quantum physics are translated into works of art that invoke both scientific curiosity and sensual experiences.

Hungarian artist Antal Kelle introduces in his article his artworks, which are based on geometrical solids constructed either with modular components or sliced parts of an unbroken solid. Kelle describes his artworks as objects at the border of scientific curiosity, playfulness, and sculpture: in many of his works the components can be moved, and thus the works themselves can be transformed into various new forms by rotating them according to the receiver's curiosity and mood. The basic underlying form of Kelle's works approximates to a regular solid, such as a cone, which may be turned into a random form or an organic statuette. Kelle's works reveal how a geometric solid may mediate various sensations when their form is altered. With modern technology the alteration of the artworks can be even remote-controlled or automatized, as his latest artistic projects indicate.

Tuuli Lähdesmäki's article forms a continuation to Vierling-Claassen's, Orosz's, Voss-Andreae's, Kelle's articles by discussing the development of abstract art and its application to public sculpture. In particular, her article focuses on the problem of representation in geometry-based monuments. Since the 1920 s, constructivist and concretist visual art movements have promoted the use of geometric forms and proportions as a basis for artistic expressions and aesthetic experience. After World War II, the ideals of geometric art were transferred to public sculpture in 
Western countries. Since then, the use of geometrical abstraction in public sculptures and monument art in particular has sparked debates and confrontations. The question of representation has been particularly problematic in the reception of monument art: geometrical abstraction has often been interpreted (or tried to be interpreted) as metonymic, metaphoric, or symbolic depictions of the person or event in honor of whom they are erected. The idea of representation and symbolic meanings are, however, against the principles of constructivist and concretist visual art movements. The article discusses from the discursive and semiotic points of view how the problem of representation has been solved in the reception of monument art based on geometric abstraction. As examples, Lähdesmäki uses two presidential monuments that were erected in Finland in the 1990s.

\section{Future Perspectives: Education Potentials in Aesthetics of Interdisciplinarity}

The Bridges community has combined forces in organizing the MoSAIC (Mathematics of Science, Art, Industry and Culture $)^{16}$ event series, sponsored by the Mathematical Sciences Research Institute (MSRI) to spur the STEAM approach (integration of Science, Technology, Engineering, Arts, and Mathematics learning for developing inquiry, critical thinking, and dialogue) among young people. As part of this program, popular aspects of Bridges events are held at university campuses throughout the USA. Thanks to international media, the attention paid to Bridges events - hosted by resident scientific and cultural institutions - strengthens also the local math-art-education communities. The Experience Workshop International Math-Art Movement, ${ }^{17}$ an independent community of mathematicians, artists, and educators, established in Hungary in 2008 preceding the Bridges Pécs 2010 conference, is still growing. Following Bridges Finland Conference in 2016, the Experience Workshop has also started education activities in Finland and is now organizing events in several locations around the world. Through this movement, tens of thousands of students and thousands of teachers have been exposed to the Bridges philosophy of interdisciplinary aesthetics and experience-oriented mathematics education through the arts.

Based on the positive experience from the Bridges community and the Experience Workshop, we encourage assessing pedagogical potentials of interdisciplinary aesthetics-based approaches and developing further 
conceptual and methodological tools for the aesthetics of interdisciplinarity in education. As successful international examples have already shown, Learning Through the Arts (LTTA) approaches can be beneficial for multiple aspects of the learning process (Elster and Ward 2007). However, these approaches have also faced criticism, as that often the subject being taught, less art itself is the focus of these processes (cf. Sotiropoulou-Zormpala 2016). To re-establish art's equal role in the interdisciplinary integrated learning process, Marina SotiropoulouZormpala (2012) set up an upgraded model of "aesthetic teaching", in which the aesthetic understanding of the subject; the utilization of multiple literacies; the meaningfulness of the learning space; interaction between logical information and moods, desires, and emotions elicited by the study topic; engaging activities; multiple approaches; and creative play take the lead. James and Marjorie Bullitt Bequette (2012) argue that interdisciplinary work in the arts and sciences can lead to curricular components that combine aesthetic and analytical modes of thinking enhancing both science and art. Respectively, Julia Marshall (2014) proposes an integrative approach to art which enables learning across the curriculum in a transdisciplinary framework by employing "Systems Thinking/New Sciences vision of art integration". Patricia Lynch (2007) notes how this kind of approach can have several positive implications for collaborative learning processes and community building. This viewed is emphasized also by Helene Robinson (2013) who argues that art integration approach may function as a valuable tool for supporting inclusion as well.

Due to the differences between the traditions, contexts, and possible goals of diverse mathematics and art education approaches, their notions of the learning process, learning activities, and collaborative learning and their approaches to teaching, problem-solving, creativity, and understanding of originality and authorship are radically different. However, through meticulous comparison several joint potentials may emerge, which can be re-contextualized and further developed into a mathematics and arts education framework based on the aesthetics of interdisciplinarity (a) to provide motivation and engagement for students and their teachers; (b) to enrich mathematics and arts learning on a meaningful way; (c) to enhance inter- and transdisciplinary STEAM learning frameworks with strong cultural embeddedness and social impact, where art is an integrative and transformative element of the STEAM concept, not just a vehicle for STEM learning. 


\section{Acknowledgements}

We want to thank László Beke, Chris Brownell, Pamela Burnard, György Darvas, Heikki Hanka, Rainer J. Hanshe, Markus Hohenwarter, Raine Koskimaa, Zsolt Lavicza, Kálmán Liptai, Pekka Neittaanmäki, Lauri Ockenstrm, Osmo Pekonen, Hannu Salmi, Marjorie Senechal, and members of the Bridges Organization, International Symmetry Association and Experience Workshop community for the discussions on the topic of this edited volume and the co-operation in related academic activities. Views on the contradictory epistemes have been elaborated in Lähdesmäki's articles entitled "Notions on Beauty in Mathematics and Arts" (2016) and "Universalist and Particularist Discourses on the Intersection of Reality, Truth, and Beauty" (2015). The history of Bridges conferences has been presented in Fenyvesi's article "Bridges: A World Community for Mathematical Art" (2016).

\section{Sources}

Barthes, R. (1973). Texte (théorie du). Encyclopaedia Universalis, 15, 1013-1017.

Belting, H. (2011). Florence and Baghdad: Renaissance art and Arabic science. Cambridge, MA: Belknap Press.

Bequette, J. W., \& Bequette, M. B. (2012). A place for art and design education in the stem conversation. Art Education, 65(2), 40-47.

Bourdieu, P. (1984). Distinction. A social critique of the judgement of taste. London: Routledge.

Cucker, F. (2013). Manifold mirrors. The crossing paths of the arts and mathematics. Cambridge: Cambridge University Press.

Darvas, G. (2007). Symmetry. Basel: Birkhäuser.

Elster, A., \& Ward, P. (2007). Learning math through the arts. In M. Emmer (Ed.), Mathematics and culture (Vol. V, pp. 167-181). Berlin: Springer.

Emmer, M. (Ed.). (2004-2012). Mathematics and culture (Vol. I-VI). Berlin: Springer.

Emmer, M. (Ed.). (2012-2014). Imagine math(s) (Vol. 1-3). Berlin: Springer. 
Emmer, M. (Ed.). (2015). Imagine math(s) (Vol. 4). Berlin: Springer.

Feenberg, A. (2010). Between reason and experience. Essays in technology and modernity. Cambridge, MA: The MIT Press.

Fenyvesi, K. (2016). Bridges: A world community for mathematical art. Mathematical Intelligencer, 38(2), 35-45.

Foucault, M. (1970). The order of things: An archaeology of the human sciences. New York: Pantheon Books.

Foucault, M. (1980). Power/knowledge. Selected interviews and other writings, 1972-1977. New York: Pantheon Books.

Goldstein, D. J. (2005). Beauty in art and mathematics: A common neural substrate or the limits of language? In R. Sarhangi \& R. V. Moody (Eds.), Renaissance Banff (pp. 93-100). Conference Proceeding of Bridges: Mathematical Connections in Art, Music, and Science, Alberta, Canada, 31 July-3 August. Phoenix: Tessellations Publishing.

Goodman, N. (1976). Languages of art. Indianapolis: Hackett.

Hadot, P. (2006). The veil of Isis: An essay on the history of the idea of nature (M. Chase Trans.). Cambridge, MA: Harvard University Press.

Henderson, L. D. (2013). The fourth dimension and non-Euclidean geometry in modern art. Cambridge, MA: The MIT Press.

Kemp, M. (1990). The science of art. Optical themes in western art from Brunelleschi to Seurat. New Haven, CT: Yale University Press.

Lähdesmäki, T. (2015). Universalist and particularist discourses on the intersection of reality, truth, and beauty. In T. Lähdesmäki \& B.

Sherringham (Eds.), Philosophies of beauty on the move. Oxford: InterDisciplinary Press.

Lähdesmäki, T. (2016). Notions on beauty in mathematics and arts. In A. Ferreira \& L. Moyse (Eds.), Cosmetic, aesthetic, prophetic: Beyond the boundaries of beauty (pp. 59-70). Oxford: Inter-Disciplinary Press.

Livio, M. (2003). The golden ratio. The story of phi. The world's most astonishing number. New York: Broadway Books.

Lu, P. J., \& Steinhardt, P. J. (2007). Decagonal and quasi-crystalline tilings in Medieval islamic architecture. Science, 315, 1106-1110. 
Lynch, P. (2007). Making meaning many ways: An exploratory look at integrating the arts with classroom curriculum. Art Education, 60(4), 3338 .

Marshall, J. (2014). Transdisciplinarity and art integration: Toward a new understanding of art-based learning across the curriculum. Studies in Art Education, 55(2), 104-127.

Robinson, H. (2013). Arts integration and the success of disadvantaged students: A research evaluation. Arts Education Policy Review, 114(4), 191-204.

Rosen, J. (2008). Symmetry rules. How science and nature are founded on symmetry. Berlin: Springer.

Rota, G.-C. (2008). Indiscrete thoughts. Boston: Birkhäuser.

Sarhangi, R. (2006). An introduction to medieval spherical geometry for artists and artisans. In R. Sarhangi \& J. Sharp (Eds.), Bridges London: Mathematics, music, art, architecture, culture (pp. 551-560). London: Tarquin Publications.

Sarhangi, R., \& Martin, B. D. (1998). The circle: A paradigm for paradox. In R. Sarhangi (Ed.), Bridges conference (pp. 93-112). Winfield, KS: Southwestern College.

Shrestha, S. (2016). In memoriam, Reza Sarhangi. Journal of Mathematics and the Arts, 10, 1-4.

Sotiropoulou-Zormpala, M. (2012). Reflections on aesthetic teaching. An approach to language arts in early childhood curriculum. Art Education, 65(1), 6-10.

Sotiropoulou-Zormpala, M. (2016). Seeking a higher level of arts integration across the curriculum. Arts Education Policy Review, 117(1), $43-54$.

Stewart, I. (1995). Nature's numbers. The unreal reality of mathematics. New York: Basic Books.

Stewart, I. (2007). Why beauty is truth. The history of symmetry. New York: Basic Books.

van Dijk, T. A. (1997). The study of discourse. In T. A. van Dijk (Ed.), Discourse as structure and process, Discourse studies: A multidisciplinary introduction (Vol. 1, pp. 1-34). London: Sage. van Fraassen, B. C. (2008). Scientific representation. Oxford: Clarendon. 
${ }^{1}$ See: http://archive.bridgesmathart.org/. Retrieved on 22 December 2016.

${ }^{2}$ On artistic consequences of the connections between the European Renaissance and the medieval Arabian science's visual investigations, see Belting (2011).

${ }^{3}$ See Reza Sarhangi's numerous articles on Abul Wafa al-Buzjani, e.g. Sarhangi (2006).

${ }^{4}$ Cf. http://www.isama.org/org/history.html . Retrieved on 24 October 2015.

${ }^{5}$ See the organization's website: http://www.isama.org/. Retrieved on 24 October 2015.

${ }^{6}$ Research professor of Computer Science at Stony Brook University (USA). Hart is also a sculptor whose work is recognized around the world for its mathematical depth and creative use of materials.

${ }^{7}$ Professor of Computer Science at the University of California, Berkeley (USA). His works in computer graphics and in geometric design have provided a bridge to the world of art. In collaboration with several sculptors of abstract geometric art, Séquin has found a new interest and yet another domain where the use of computer-aided tools can be explored and where new frontiers can be opened through the use of such tools. ${ }^{8}$ Professor of University of Waterloo (Canada), and former main editor of Journal of Mathematics and the Arts. The focus of Kaplan's research is on the relationships between computer graphics, art, and design, with an emphasis on applications to graphic design, illustration, and architecture. ${ }^{9}$ A former researcher of Jet Propulsion Laboratory, and the founder of Tessellations, a company that specializes in products that combine art and mathematics. He is an internationally renowned author of activity books on art and mathematics and a mathematical artist, whose work has been shown in numerous exhibits in the US, Canada, and Europe.

${ }^{10}$ The virtual galleries of Bridges Art Exhibit can be accessed here:

http://bridgesmathart.org/bridges-galleries/art-exhibits/ . Retrieved on 24 October 2015.

${ }^{11} \mathrm{Cf}$. http://www.nexusjournal.com/the-nexus-conferences.html .

Retrieved on 24 October 2015.

${ }^{12} \mathrm{Cf}$. http://www.symmetry.hu and http://symmetry-us.com /. Retrieved on 24 October 2015.

${ }^{13}$ Cf. http://www.math-art.eu /. Retrieved on 24 October 2015.

${ }^{14}$ See: http://sigmaa.maa.org/arts/index.html . Retrieved on 24 October 2015 . 
${ }^{15}$ About the Bridges Organization's Board of Directors, see:

http://bridgesmathart.org/about/ . Retrieved on 26 November 2016.

${ }^{16}$ See http://bridgesmathart.org/mosaic/ . Retrieved on 24 October 2015.

${ }^{17}$ See http://www.experienceworkshop.org . Retrieved on 24 October

2015. 